\title{
ENHANCED RECOVERY AFTER SURGERY PROTOCOL (ERAS) FOR ELECTIVE COLORECTAL SURGERY IN THE UNIVERSITY HOSPITAL OF GUADALAJARA, SPAIN: A PROSPECTIVE COHORT STUDY
}

M. Cabellos Olivares, V. Jiménez Guitián, M. Labalde Martínez, M. Torralba , J. R. Rodriguez Fraile, J.C. Atance Martínez

INTRODUCTION: The use of ERAS pathways has proven to reduce care time after colorectal surgery. The aim of this study is to evaluate the effectiveness of an ERAS program based on hospital length of stay (LOS), readmission rates and postoperative Clavien-Dindo complications.

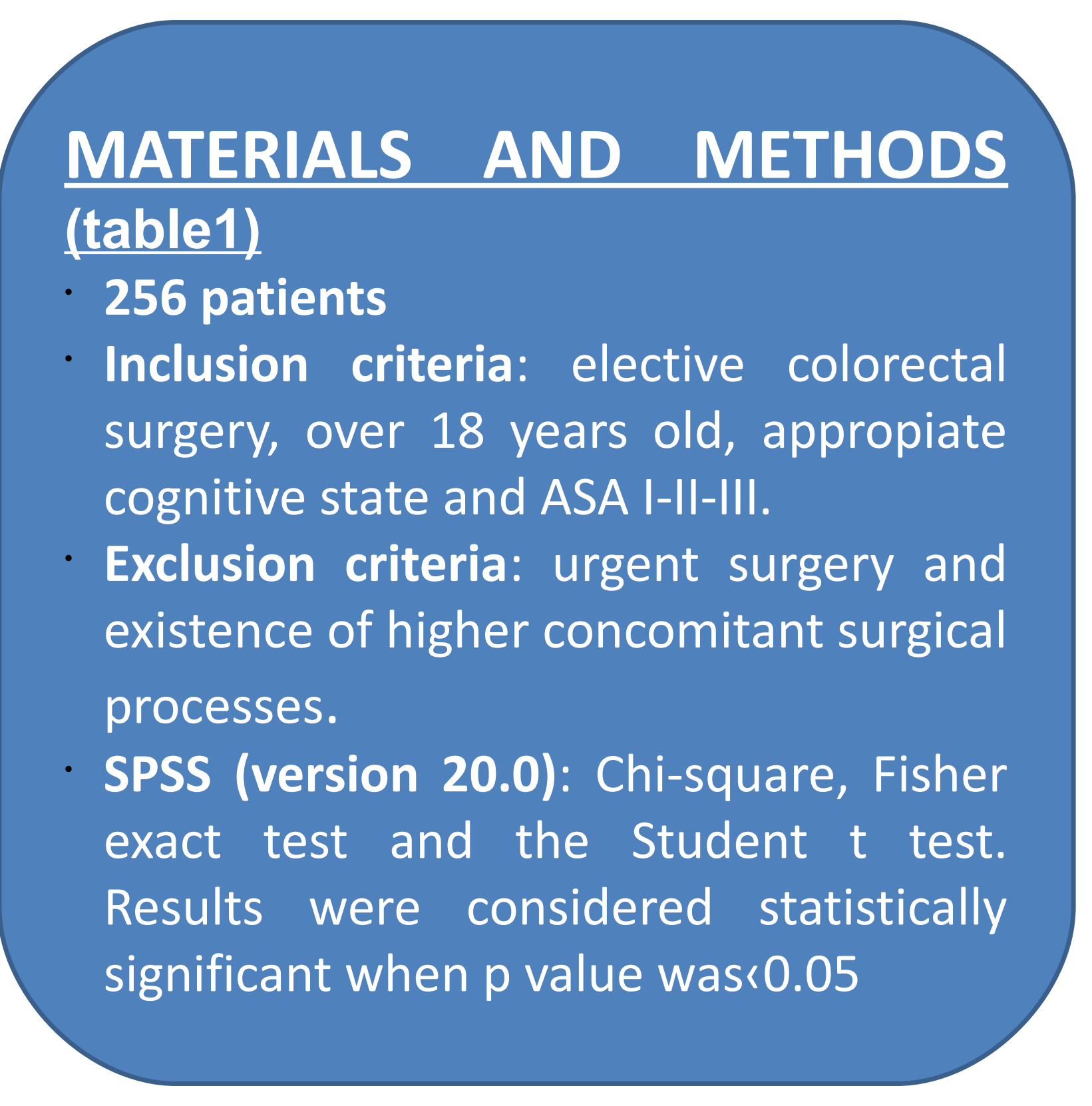

RESULTS

Average compliance: $74.3 \%$

Table 2: preERAS and ERAS group

\begin{tabular}{|l|c|c|c|}
\hline & Pre ERAS $(\mathbf{n} \mathbf{1 3 5})$ & ERAS $(\mathrm{n} 121)$ & 0.49 \\
\hline With complications & $49(36.3 \%)$ & $38(31.4 \%)$ & 0.174 \\
\hline Clavien Dindo: & $21(15.5 \%)$ & $8(6.6 \%)$ & \\
\hline 1 & $13(9.6 \%)$ & $17(14 \%)$ & \\
\hline 2 & $14(10.4 \%)$ & $11(9.1 \%)$ & 0.833 \\
\hline 4 & 0 & 0 & 0.134 \\
\hline 5 & $1(0.7 \%)$ & $2(1.7 \%)$ & 0.498 \\
\hline Reinterventions & $9(7.4 \%)$ & $11(8.1 \%)$ & $\mathbf{0 . 0 1 8}$ \\
\hline ICU & 0 & $2(1.7 \%)$ & 0.756 \\
\hline Mortality & $1(0.7 \%)$ & $2(1.7 \%)$ & \\
\hline LOS & $11 \pm 3.8$ & $9.78 \pm 3.69$ & $12(9.9 \%)$ \\
\hline 30 days readmissions & $15(11.1 \%)$ & & \\
\hline
\end{tabular}

CONCLUSIONS: ERAS program shortened LOS without increasing 30-days readmission rates. We need to increase patients' compliance to the protocol to improve our results in future studies.

Table 1: preERAS and ERAS group

\begin{tabular}{l|c|c|c|} 
& $\begin{array}{c}\text { Pre ERAS } \\
(\mathrm{n} 135)\end{array}$ & $\begin{array}{c}\text { ERAS } \\
(\mathrm{n} \mathrm{121})\end{array}$ & $p$ \\
\hline Age & $68.43 \pm 12.26$ & $68.43 \pm 13.38$ & 0.161 \\
\hline Men & $41(30.4 \%)$ & $44(36.7 \%)$ & 0.309 \\
Women & $94(69.7 \%)$ & $77(63.6 \%)$ & \\
\hline ASA 1 & $10(7.4 \%)$ & $12(9.9 \%)$ & 0.325 \\
\hline ASA 2 & $86(64.7 \%)$ & $66(54.6 \%)$ & \\
ASA 3 & $39(28.9 \%)$ & $43(35.5 \%)$ & \\
\hline $\begin{array}{l}\text { Laparoscopy } \\
\text { Time (min) }\end{array}$ & $27(20 \%)$ & $45(37.2 \%)$ & $\mathbf{0 . 0 0 6}$ \\
\hline Fluid therapy & $2144 \pm 861$ & $1576 \pm 869$ & $<0.56$ \\
\hline $\begin{array}{l}\text { Ambulation } \\
\text { DPO1 }\end{array}$ & $2(1.5 \%)$ & $52(43 \%)$ & $<\mathbf{0 . 0 0 1}$ \\
\hline $\begin{array}{l}\text { Oral liquid } \\
\text { diet DPO1 }\end{array}$ & $13(9.6 \%)$ & $45(37.2 \%)$ & $<\mathbf{0 . 0 0 1}$ \\
\hline $\begin{array}{l}\text { Opioids } \\
\text { DPO1 }\end{array}$ & $106(78.5 \%)$ & $44(36.4 \%)$ & $<\mathbf{0 . 0 0 1}$ \\
\hline
\end{tabular}

